\title{
Sclareolide enhances gemcitabine-induced cell death through mediating the NICD and Gli1 pathways in gemcitabine-resistant human pancreatic cancer
}

\author{
SHENG CHEN $^{1 *}$, YE WANG $^{2 *}$, WEN-LONG ZHANG $^{1}$, MAO-SHENG DONG $^{1}$ and JIAN-HUA ZHANG ${ }^{1}$ \\ ${ }^{1}$ Department of General Surgery, The General Hospital of the PLA Rocket Force, Beijing 100088; \\ ${ }^{2}$ Department of Pathology, China-Japan Friendship Hospital, Beijing 100029, P.R. China
}

Received November 16, 2015; Accepted November 11, 2016

DOI: $10.3892 / \mathrm{mmr} .2017 .6182$

\begin{abstract}
Pancreatic cancer is a type of cancer, which rapidly develops resistance to chemotherapy. Gemcitabine is the treatment used clinically, however, gemcitabine resistance leads to limited efficacy and patient survival rates of only a few months following diagnosis. The aim of the present study was to investigate the mechanisms underlying gemcitabine resistance in pancreatic cancer and to select targeted agents combined with gemcitabine to promote the treatment of pancreatic cancer. Panc-1 and ASPC-1 human pancreatic cancer cells (HPCCs) were used to establish the experimental model, and HPCCs were exposed to gemcitabine of serially increased concentrations to generate gemcitabine-resistant cells (GR-HPCCs). The anticancer effect of gemcitabine combined with sclareolide was then assessed. Epithelial to mesenchymal transition (EMT), human equilibrative nucleoside transporter 1 (hENT1) and ribonucleoside diphosphate reductase 1 (RRM1) were detected in the HPCCs and GR-HPCCs, and the mechanisms were investigated. Sclareolide resensitized the GR-HPCCs to gemcitabine. The expression levels of hENT1 and RRM1 were lower and higher, respectively, in GR-HPCCs, compared with HPCCs. Sclareolide upregulated hENT1, downregulated
\end{abstract}

Correspondence to: Dr Jian-Hua Zhang or Dr Sheng Chen, Department of General Surgery, The General Hospital of the PLA Rocket Force, 16 Xinjie Kouwai Street, Xicheng, Beijing 100088, P.R. China

E-mail: jh_zhang1963@sina.com

E-mail: shengc_1972@sina.com

*Contributed equally

Abbreviations: EMT, epithelial to mesenchymal transition; GR-HPCC, gemcitabine-resistant human pancreatic cancer cell; HPCC, human pancreatic cancer cell; hENT1, human equilibrative nucleoside transporter 1; RRM1, ribonucleoside diphosphate reductase 1

Key words: sclareolide, gemcitabine, epithelial to mesenchymal transition, gemcitabine-resistant human pancreatic cancer cells
RRM1 and inhibited gemcitabine-induced EMT through the TWIST1/Slug pathway in the GR-HPCCs. In addition, sclareolide mediated the NOTCH 1 intracellular cytoplasmic domain (NICD)/glioma-associated oncogene 1 (Gli1) pathway, which triggered TWIST1/Slug-hENT1/RRM1 signaling and resensitized GR-HPCCs to gemcitabine. Finally, sclareolide resensitized GR-HPCCs to gemcitabine through inducing apoptosis; in vivo, the co-administraion of sclareolide and gemcitabine effectively suppressed tumor growth. Sclareolide may be a novel agent in combination with gemcitabine for the treatment of gemcitabine-resistant pancreatic cancer, which resensitizes GR-HPCCs to gemcitabine through mediating NICD and Gli1.

\section{Introduction}

Pancreatic cancer is a life-threatening form of cancer with a $90 \%$ mortality rate, ranking as the fourth leading cause of cancer-associated mortality in China (1). At present, the primary form of treatment for pancreatic cancer is surgery combined with chemotherapy (2). Gemcitabine is the first-line chemotherapeutic drug used clinically for the treatment of pancreatic cancer and, although gemcitabine can significantly inhibit the growth of pancreatic cancer, the emergence of gemcitabine resistance in reduces the therapeutic effect of gemcitabine, leading to shortened patient survival rates, which for the majority is only a few months $(3,4)$. Therefore, clarifying the mechanism underlying gemcitabine resistance is required to improve treatment. In order to enhance the therapeutic effect of gemcitabine through the resensitization of gemcitabine to pancreatic cancer, investigations have focused on combination chemotherapy; however, few drugs have been screened, indicating the requirement for a novel and efficient combination drug.

Human equilibrative nucleoside transporter 1 (hENT1) is a bidirectional channel, which is the carrier of pyrimidine nucleotides, the gemcitabine, capecitabine and 5-fluorouracil may bind to pyrimidine nucleotides and move into and out of the cell (5). Previous studies have found that hENT1 is important in the resistance of gemcitabine and in patients treated with gemcitabine chemotherapy for pancreatic cancer, as patients who have higher expression levels of hENT1 have increased 
survival rates, compared with patients who have lower expression levels of hENT1 $(5,6)$. These findings suggest that hENT1 may be a target of gemcitabine, and selection of an hENT1 agonist may enhance the therapeutic effect of gemcitabine. Previous investigations have revealed that ribonucleoside diphosphate reductase 1 (RRM1) is a gemcitabine-targeting molecule; when RRM1 was at expressed at a lower level, patients with pancreatic cancer were more sensitive to gemcitabine chemotherapy, and the expression level of RRM1 was higher in gemcitabine-resistant patients (7-9). Therefore, in order to inhibit gemcitabine resistance, use of an hENT1 agonist can inhibit the expression of RRM1.

Epithelial to mesenchymal transition (EMT) describes the process by which epithelial cells convert into cells with a mesenchymal phenotype through specific pathways. EMT is important in embryonic development, chronic inflammation, tissue remodeling, cancer metastasis and several fibrotic diseases (10-12). By EMT, epithelial cells lose cell polarity and lose connections with the basement membrane in the epithelial phenotype, and obtain higher migratory, invasive, anti-apoptotic and extracellular matrix degradation capacities in the mesenchymal phenotype (10). It has been reported that EMT is important in gemcitabine resistance in pancreatic cancer; in gemcitabine-resistant pancreatic cancer, EMT is in the active state $(11,12)$. Therefore, the prevention of gemcitabine-resistance-induced EMT may be an effective therapeutic strategy.

Sclareolide is a sesquiterpene lactone and a natural product derived from various plant sources, including Salvia sclarea, Salvia yosgadensis and cigar tobacco $(13,14)$. At present, sclareolide is predominantly used for cosmetics and weight-reduction products, with almost no applications in the medical field. In the present study, whether sclareolide can resensitize pancreatic cancer to gemcitabine was investigated. Sclareolide promoted gemcitabine-induced cell death of pancreatic cancer cells through apoptosis, the upregulated expression of hENT1, downregulated expression of RRM1 and inhibition of the EMT through the TWIST1/Slug pathway, which was mediated by NICD/Glil signals. The results of the in vivo experiments supported the in vitro experiments. Therefore, sclareolide combined with gemcitabine may provide a novel chemotherapeutic strategy for gemcitabine-resistant pancreatic cancer.

\section{Materials and methods}

Cell culture. Panc-1 and ASPC-1 human pancreatic cancer cells (HPCCs) were obtained from the American Type Culture Collection (Manassas, VA, USA). All cells were cultured in DMEM (Hyclone; GE Healthcare Life Sciences, Logan, UT, USA) with $10 \%$ fetal bovine serum (FBS) (Hyclone; GE Healthcare Life Sciences), $2 \mathrm{Mm}$ L-glutamine, $100 \mathrm{U} / \mathrm{ml}$ penicillin and $100 \mathrm{mg} / \mathrm{ml}$ streptomycin, at $5 \% \mathrm{CO}_{2}$ and $37^{\circ} \mathrm{C}$. All cell culture reagents were purchased from Gibco; Thermo Fisher Scientific, Inc. (Waltham, MA, USA). The Panc-1 and ASPC-1 cells $\left(1 \times 10^{4}\right)$ were exposed to gemcitabine at serially increased concentrations, with an initial concentration of $10 \mathrm{nM}$, to generate gemcitabine-resistant cells. Following 2 weeks of adaptation, the concentration was doubled. The cells were adapted to a final gemcitabine concentration of $640 \mathrm{nM}$, termed gemcitabine-resistant (GR)-Panc-1 cells and GR-ASPC-1 cells.
Reverse transcription-quantitative polymerase chain reaction (RT-qPCR) analysis. The total RNA expression levels of hENT1 and RRM1 were determined using a previously described protocol $(6,8)$. Briefly, the total RNA of cell was extracted by TRIzol (Invitrogen; Thermo Fisher Scientific, Inc.) according to the protocol. Triplicates of each gene and each specimen were used, with GAPDH as an internal standard. The single-strand cDNA for PCR template was synthesized from $10 \mu \mathrm{g}$ of total RNA by Illumina TotalPrep RNA amplification kit (Ambion; Thermo Fisher Scientific, Inc.). StepOne ${ }^{\mathrm{TM}}$ Real-Time PCR system (Applied Biosystems; Thermo Fisher Scientific, Inc.) was used in the RT-PCR assay. The RT-PCR was performed with a total reaction volume of $20 \mu \mathrm{l}$, including $10 \mu \mathrm{l}$ Power SYBR Green PCR Master mix (Applied Biosystems; Thermo Fisher Scientific, Inc.), 5 pmol of forward and reverse primer respectively and $2 \mu \mathrm{l}$ of cDNA. Threshold cycle $(\mathrm{Ct})$ was observed in the amplification with 35 cycles of $1 \mathrm{~min}$ at $95^{\circ} \mathrm{C}, 1 \mathrm{~min}$ at $58^{\circ} \mathrm{C}$, and $1 \mathrm{~min}$ at $72^{\circ} \mathrm{C}$. And the relative of mRNA expression levels was calculated by the relative quantitation method $2^{-\Delta \Delta C q}(15)$. The fold change to control sample of each samples was calculated. Relative gene quantification was performed using StepOne ${ }^{\mathrm{TM}}$ software 2.1 (Applied Biosystems; Thermo Fisher Scientific, Inc.). The following primers were used: GAPDH, forward 5'-CGGAGT CAACGGATTTGGTCGTAT-3' and reverse 5'-AGCCTTCTC CATGGTGGTGAAGAC-3'; hENT1, forward 5'-AGCAGG CAAAGAGGAATCTGGAGT-3' and reverse 5'-GAAGGC AAAGGCAGCCATGAAGAA-3'; RRM1, forward 5'-CAT CCACATTGCTGAGCCTA-3' and reverse 5'-GATTAGCCG CTGGTCTTGTC-3'.

Western blot analysis. For each sample, $5 \times 10^{6}$ cells were lysed for $30 \mathrm{~min}$ in lysis buffer (Beyotime Institute of Biotechnology, Beijing, China) on ice, and the debris was centrifuged at $12,000 \times \mathrm{g}$ for $12 \mathrm{~min}$ at $4^{\circ} \mathrm{C}$. A BCA assay (Beyotime Institute of Biotechnology) was used to determine the protein concentration, following which $30 \mu \mathrm{g}$ proteins were separated using 8-15\% SDS-PAGE and blotted onto a PVDF membrane. The membrane was blocked using blocking solution of 5\% nonfat dry milk in PBST $(0.05 \%$ Tween 20 in PBS). The membrane was then incubated with primary antibodies for $2 \mathrm{~h}$ at $37^{\circ} \mathrm{C}$ at a 1:1,000 dilution, following which the PVDF membrane was washed three times for $10 \mathrm{~min}$ in PBST. The membrane was then incubated with secondary antibodies for $1 \mathrm{~h}$ at $37^{\circ} \mathrm{C}$ at a $1: 10,000$ dilution, following which the PVDF membrane was washed three times for $10 \mathrm{~min}$ in PBST. All antibodies were purchased from Santa Cruz Biotechnology, Inc. (Santa Cruz, CA, USA), the details of antibodies were followed: hENT1 (sc-48489, polyclonal, goats anti-human), GAPDH (sc-293335, monoclonal, mouse anti-human), RRM1 (sc-22786, monoclonal, rabbit anti-human), Twist1 (sc-134136, polyclonal, mouse anti-human), Slug (sc-166902, monoclonal, mouse anti-human), E-cadherin (sc-33743, polyclonal, rabbit anti-human), $\alpha$-SMA (sc-53142, monoclonal, mouse anti-human), NICD (sc-74276, monoclonal, mouse anti-human), Gli1 (sc-20687, polyclonal, rabbit anti-human), PARP (sc-27034, polyclonal, goats anti-human), Capase3 (sc-1224, polyclonal, goats anti-human), goats IgG (sc-2419), mouse IgG (sc-516176), rabbit IgG (sc-2794). 
Cell viability assay. A CCK8 was used to assess cell viability. The cells $\left(10^{4} /\right.$ well $)$ were plated on a 96 -well plate and attached overnight, the cells were treated with the drugs for $24 \mathrm{~h}$, following which the medium was removed and the cells were washed three times with PBS. Subsequently, $90 \mu 1$ DMEM and $10 \mu \mathrm{l} \mathrm{CCK8}$ were added to each well, and incubated for $1.5 \mathrm{~h}$ at $37^{\circ} \mathrm{C}$. A microplate reader was used to measure the optical density values at $450 \mathrm{~nm}$.

Trypan blue assay. To the adequately suspended treated cells, $0.4 \%$ (w/v) Trypan blue solution was added, for which the volume ratio of cell suspension to Trypan blue solution was 9:1. The cells were counted under a microscope, with dead cells failing to exclude the dye, and the death rate was calculated as follows: Total death rate $=$ (number of dead cells/total cells)x $100 \%$.

Transfection experiment. Transient transfection of cells with small interfering (si)RNAs and plasmids were performed using Lipofectamine 2000 (Invitrogen Life Technologies; Thermo Fisher Scientific, Inc.) according to the manufacturer's protocol. At $36 \mathrm{~h}$ post-transfection, the drugs were added to the cells, which were collected following a $24 \mathrm{~h}$ period for western blot analysis. The sequences of (si)RNAs were as follows: hENT1, 5'-AUGACAUUGUUGAAGAUGGCA-3'), Twist1, 5'-AAACAUUUGUUUUAAGGAGAA-3'); Slug, 5'-ACUAAUGGGGCUUUCUGAGCC-3'); NICD, (5'-UAA AGAGAGAAUAUCGUAGUC-3'); Gli1, (5'-UUUCAUACA CAGAUUCAGGCU-3').

Cell invasion assay. A BioCoat Matrigel invasion chamber system (Corning Incorporated, NY, USA) was used to determine cell invasion. In a Transwell plate, the lower chamber was filled with culture medium without cells, and the upper chamber was filled with cell suspension $\left(1 \times 10^{5}\right)$ and medium containing $10 \%$ FBS. The Transwell plate was incubated at $37^{\circ} \mathrm{C}$ for $24 \mathrm{~h}$. The cells adherent to upper chamber surface were removed, and the cells adherent to lower chamber surface were stained with $4 \%$ paraformaldehyde for $15 \mathrm{~min}$, rinsed with water and dried. Crystal violet was extracted with $50 \%$ ethanol containing $0.1 \mathrm{M}$ sodium citrate, and the absorbance was measured at $600 \mathrm{~nm}$.

Detection of apoptosis. Following treatment, the cells were incubated with Annexin V-fluorescein isothiocyanate (FITC) and propidium iodide (PI; Beyotime Institute of Biotechnology) at room temperature for $15 \mathrm{~min}$. A FACScan flow cytometer was used for analysis of the apoptotic ratio.

Xenograft model. A total of 30 male 6-week-old BALB/c nude mice were purchased from the Institute of Zoology, Chinese Academy of Sciences (Beijing, China). All the mice were fed in the specific-pathogen free environment, the plastic cage was sealed with an air filter, animal isolators, air laminator, and air laminar flow chamber were equipped, and the feeding environment with temperature $24-28^{\circ} \mathrm{C}$, relative humidity $50 \sim 60 \%$, ventilation required 10 to 15 times per hour, natural circadian light. and the mice were given the sterilized food, and the water with bacitracin $(4 \mathrm{~g} / 1)$ and neomycin $(4 \mathrm{~g} / \mathrm{l})$. All animal experiments were performed according to the guidelines of the
Institutional Animal Care and Use Committee of the Institute of Zoology, Chinese Academy of Sciences. Each BALB/c nude mouse was subcutaneously inoculated with $5 \times 10^{6}$ Panc- 1 or GR-Panc-1 cells in their right and left hind footpads. At 2 days post-inoculation, the mice inoculated with Panc-1 cells were administered with $10 \mathrm{mg} / \mathrm{kg}$ gemcitabine three times every day via intraperitoneal injection. The mice inoculated with GR-Panc-1 cells were administered with $10 \mathrm{mg} / \mathrm{kg}$ gemcitabine or co-administered with $100 \mathrm{mg} / \mathrm{kg}$ sclareolide and $10 \mathrm{mg} / \mathrm{kg}$ gemcitabine three times every day via intraperitoneal injection, with the sclareolide injected $2 \mathrm{~h}$ prior to the gemcitabine. The sclareolide and gemcitabine were dissolved in saline. The mice were sacrificed by anesthesia with pentobarbital at 2, 3 and 4 weeks after the cell inoculation, and the tumor volumes were measured.

TUNEL assay. The tumors were immersed in $4 \%$ paraformaldehyde for $24 \mathrm{~h}$, and were then dehydrated in $30 \%$ sucrose solution, following which the tissues were paraffin-embedded for sectioning $(10 \mu \mathrm{m})$. The sections were treated using an in situ Cell Death Detection kit (Roche Diagnostics, Indianapolis, IN, USA) according to the manufacturer's protocol.

Statistical analysis. The data are represented as the mean \pm standard deviation from triplicate experiments. All the data were processed by SPSS version 19.0 (IBM SPSS, Armonk, NY, USA). Two-way analysis of variance was used to analyze the variance of different groups. $\mathrm{P}<0.05$ was considered to indicate a statistically significant difference.

\section{Results}

Sclareolide enhances gemcitabine-induced GR-HPCC death. The GR-Panc-1 and GR-ASPC-1 cells were induced with increasing concentrations of gemcitabine from $10 \mathrm{~nm}$. The GR-HPCCs (GR-Panc-1 and GR-ASPC-1 cells) and HPCCs (Panc-1 and ASPC-1 cells) were treated with different concentrations of gemcitabine. No significant alterations in cell viability or cell death ratio were observed in the GR-HPCCs following exposure to increasing gemcitabine concentrations. For the HPCCs, the cell viability decreased and the cell death ratio increased with increased gemcitabine concentrations (Fig. 1A). The GR-HPCCs were treated with different concentrations of gemcitabine combined with $10 \mu \mathrm{M}$ sclareolid. At a gemcitabine concentration of $0.5 \mu \mathrm{M}$, the cell viability and cell death ratio were significantly altered, compared with the cells treated with gemcitabine alone. The optimal concentration of gemcitabine was $1 \mu \mathrm{M}$ (Fig. 1B). Similarly, GR-HPCCs were treated with different concentrations of sclareolide combined with $1 \mu \mathrm{M}$ gemcitabine. At a sclareolide concentration of $5 \mu \mathrm{M}$, the cell viability and cell death ratio were significantly altered, compared with the cells treated with gemcitabine alone, with an optimal sclareolide concentration of $10 \mu \mathrm{M}$ (Fig. 1C). These results indicated that $10 \mu \mathrm{M}$ sclareolide enhanced gemcitabine-induced GR-HPCC death.

Sclareolide upregulates the expression of hENT1 and downregulates the expression of RRMI in GR-HPCCs. Several 

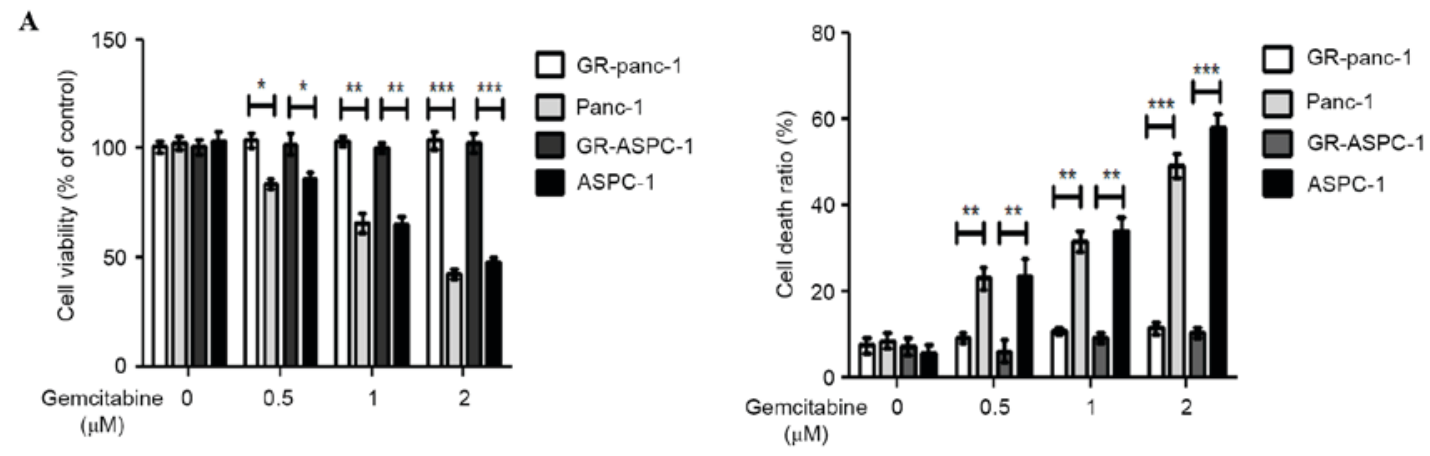

B
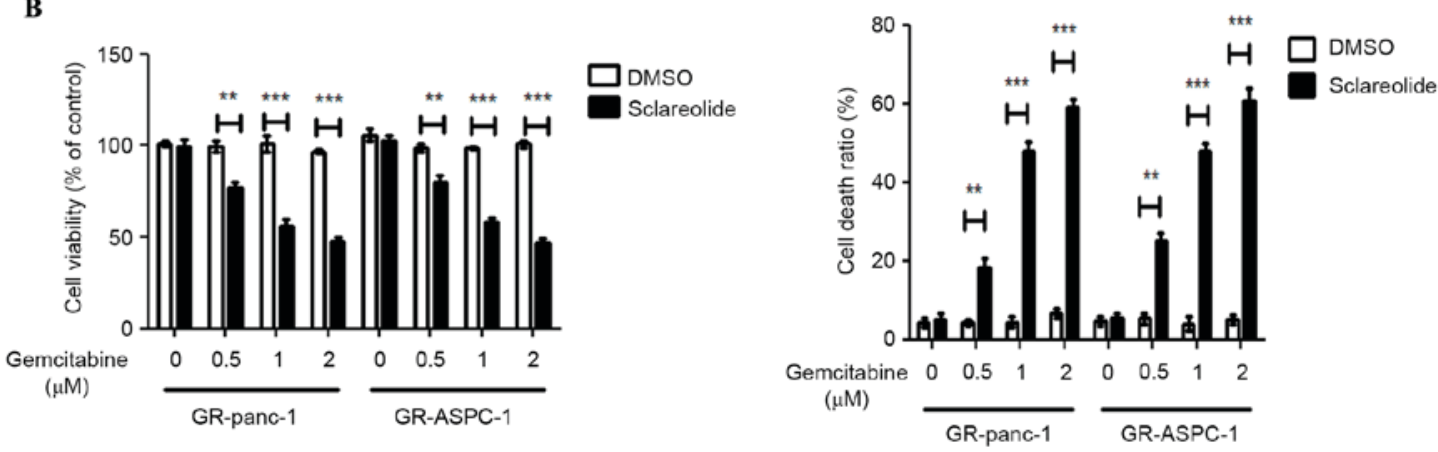

C
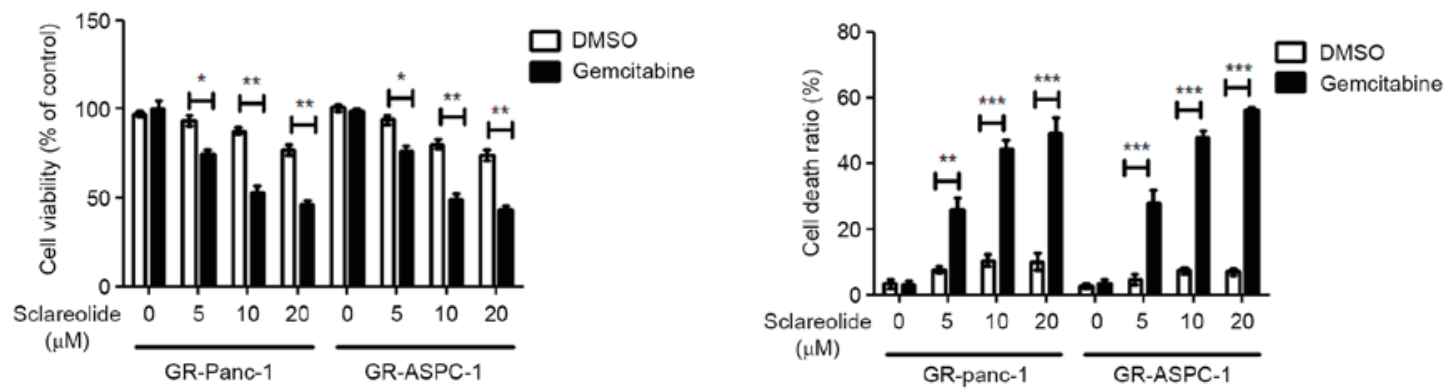

Figure 1. Sclareolide enhances gemcitabine-induced GR-HPCC death. (A) HPCCs and GR-HPCCs were treated with different concentrations of gemcitabine for $24 \mathrm{~h}$. (B) GR-HPCCs were pretreated with $0.1 \%$ DMSO or $10 \mu \mathrm{m}$ sclareolide for $2 \mathrm{~h}$ and then treated with different concentrations of gemcitabine for $24 \mathrm{~h}$. (C) GR-HPCCs were pretreated with different concentrations of sclareolide for $2 \mathrm{~h}$ and then treated with $1 \mu \mathrm{m}$ gemcitabine or $0.1 \%$ DMSO for $24 \mathrm{~h}$. Cell viability was measured using a CCK8 assay and the cell death ratio was analyzed using Trypan blue. ${ }^{*} \mathrm{P}<0.05 ;{ }^{* *} \mathrm{P}<0.01$ and ${ }^{* * *} \mathrm{P}<0.005$. GR- HPCCs, gemcitabine-resistant human pancreatic cancer cells.

studies have reported that hENT1 and RRM1 are important in the treatment of pancreatic cancer with gemcitabine $(5,6,8)$. HENT1 is a transporter of gemcitabine, and RRM1 is a target of gemcitabine. Higher expression levels of hENT1 and lower expression levels of RRM1 may assist in the treatment of pancreatic cancer with gemcitabine. The mRNA and protein expression levels of hENT1 were lower in the GR-HPCCs, compared with the HPCCs, and the mRNA and protein expression levels of RRM1 were higher in the GR-HPCCs, compared with the HPCCs. This suggested that hENT1 and RRM1 were important in gemcitabine resistance (Fig. 2A and B). The HPCCs and GR-HPCCs were treated with gemcitabine combined with sclareolide, and the results showed that sclareolide upregulated the mRNA and protein expression levels of hENT1 and downregulated the mRNA and protein expression levels of RRM1 (Fig. 1A and B). Knocking down hENT1 by transfection of the GR-Panc-1 cells with siRNA resulted in a reduction in the cell death ratio induced by gemcitabine combined with sclareolide, compared with the cells transfected with control siRNA (Fig. 2C). The overexpression of RRM1 also inhibited the cell death ratio induced by gemcitabine combined with sclareolide in the GR-Panc-1 cells (Fig. 2D). These results showed that sclareolide enhanced gemcitabine-induced GR-HPCC death through targeting hENT1 and RRM1.

Sclareolide suppresses the EMT phenotype in GR-HPCC. Previous studies have reported that EMT is in the active state in gemcitabine-resistant pancreatic cancer. In order to confirm whether sclareolide can affect the EMT in GR-HPCCs, the epithelial cell marker, E-cadherin, and mesenchymal cell marker, $\alpha$-smooth muscle actin (SMA) were detected in the HPCCs and GR-HPCCs, and the expression levels of TWIST1 and Slug were examined. The HPCCs and GR-HPCCs were treated with gemcitabine alone or combined with sclareolide, the results showed that the expression level of E-cadherin was lower in the GR-HPCCs, compared with the HPCCs, and the expression of $\alpha$-SMA was higher, indicating that EMT was in 
$\mathbf{A}$
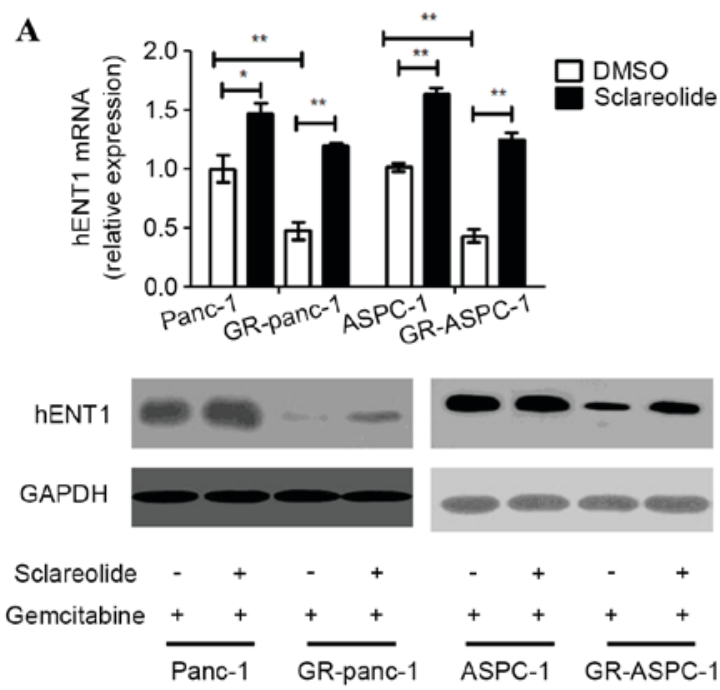

C
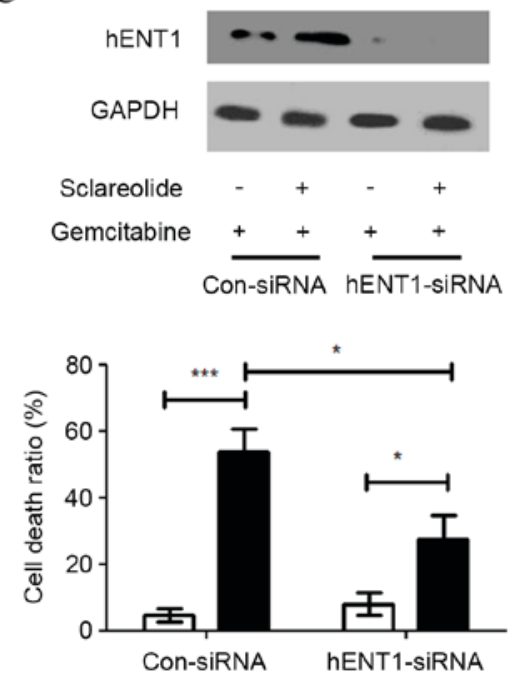

B
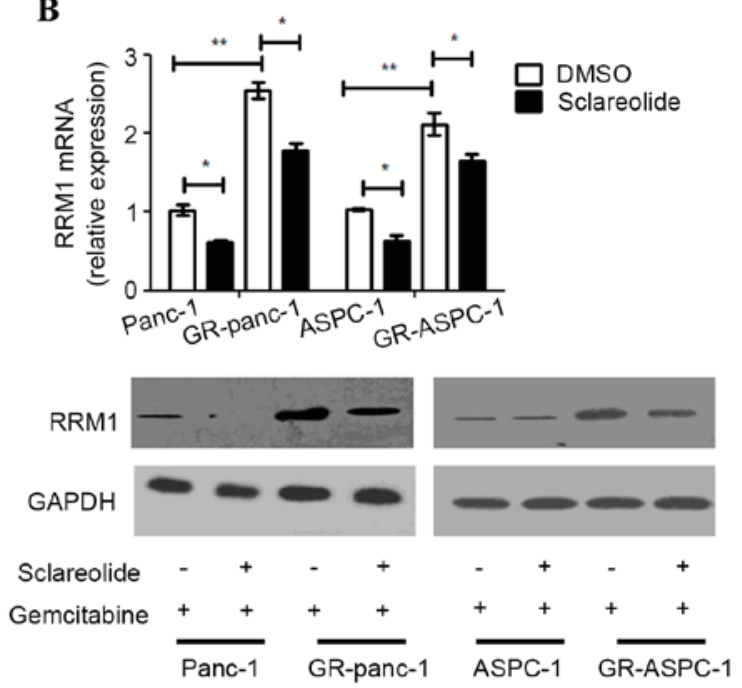

D

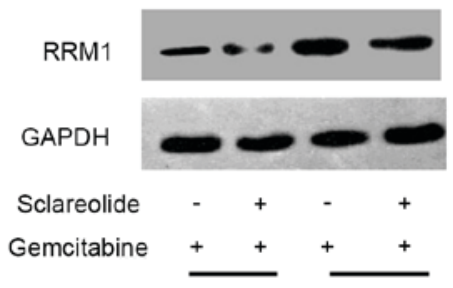

Con-pcDNA3.1 RRM1-pcDNAA3.1

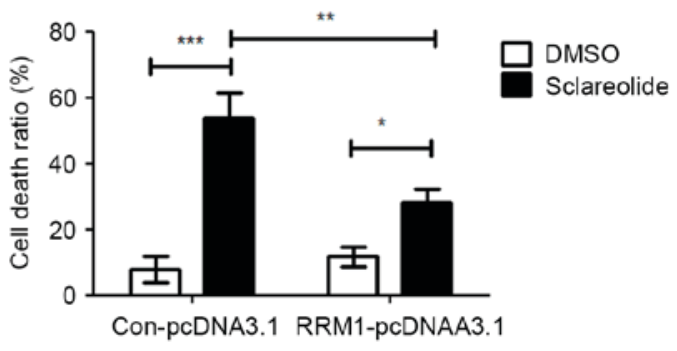

Figure 2. Sclareolide upregulates hENT1 and downregulates RRM1 in GR-HPCC, and enhances gemcitabine-induced GR-HPCC death through hENT1 and RRM1 signals. HPCC and GR-HPCC were treated with $1 \mu \mathrm{m}$ gemcitabine alone or co-treated with $10 \mu \mathrm{m}$ sclareolide $(2 \mathrm{~h}$ pretreatment $)$ and $1 \mu \mathrm{m}$ gemcitabine for $24 \mathrm{~h}$. Sclareolide (A) recovered the suppression of the mRNA and protein expression levels of hENT1, and (B) recovered the activation of the mRNA and protein expression levels of RRM1 in the GR-HPCCs. (C) GR-Panc-1 cells were transfected with control siRNA or hENT1-siRNA, and treated with $1 \mu \mathrm{m}$ gemcitabine alone or co-treated with $10 \mu \mathrm{m}$ sclareolide ( $2 \mathrm{~h}$ pretreatment) and $1 \mu \mathrm{m}$ gemcitabine for $24 \mathrm{~h}$. The cell death ratio was analyzed using Trypan blue. (D) GR-Panc-1 cells were transfected with the control plasmid (con-pcDNA3.1) or RRM1-plasmid (RRM1-pcDNA3.1), and treated with $1 \mu \mathrm{m}$ gemcitabine with or without $10 \mu \mathrm{m}$ sclareolide $\left(2 \mathrm{~h}\right.$ pretreatment) for $24 \mathrm{~h}$. The cell death ratio was analyzed using Trypan blue. ${ }^{*} \mathrm{P}<0.05 ;{ }^{* * *} \mathrm{P}<0.01$ and ${ }^{* * *} \mathrm{P}<0.005$. GR-HPCCs, gemcitabine-resistant human pancreatic cancer cells; hENT1, human equilibrative nucleoside transporter 1; RRM1, ribonucleoside diphosphate reductase 1; siRNA, small interfering RNA.

the active state in the GR-HPCCs. In addition, the expression levels of TWIST1 and Slug were higher in the GR-HPCCs, compared with the HPCCs, and all alterations were inhibited by sclareolide (Fig. 3A). Several studies have reported that TWIST1 and Slug are mediators of EMT as transcriptional factors, and the expression levels of TWIST1 and Slug have been found to be higher in several cancer EMT phenotypes $(16,17)$. In the present study, on detecting the GR-HPCC EMT phenotype through knocking down TWIST1 and Slug by siRNA in the GR-Panc- 1 cells, the expression of $\alpha$-SMA was inhibited and the expression of E-cadherin was enhanced. In addition, the expression level of hENT1 was inhibited and that of RRM1 was enhanced (Fig. 3B and C). Additionally, the cell death ratio was increased in GR-Panc-1 cells induced by gemcitabine following the knock down of TWIST1 and Slug (Fig. 3D and E). The invasive ability of the GR-HPCCs was more marked, compared with that of the HPCCs, and sclareolide suppressed the invasive ability of the GR-HPCCs (Fig. 3F). These results indicated that sclareolide suppressed the GR-HPCC EMT phenotype and resensitized GR-HPCCs to gemcitabine through the TWIST1 and Slug pathway.

Sclareolide resensitizes GR-HPCsC to gemcitabine through inhibiting NICD/Gli1 signals. Several studies have reported that NICD and Gli1 can mediate TWIST1 and Slug (18-20). In order to fully understand the upstream mediators of TWIST1 and SLUG, the expression levels of NICD and Gli1 were detected in HPCCs and GR-HPCCs, which were treated 


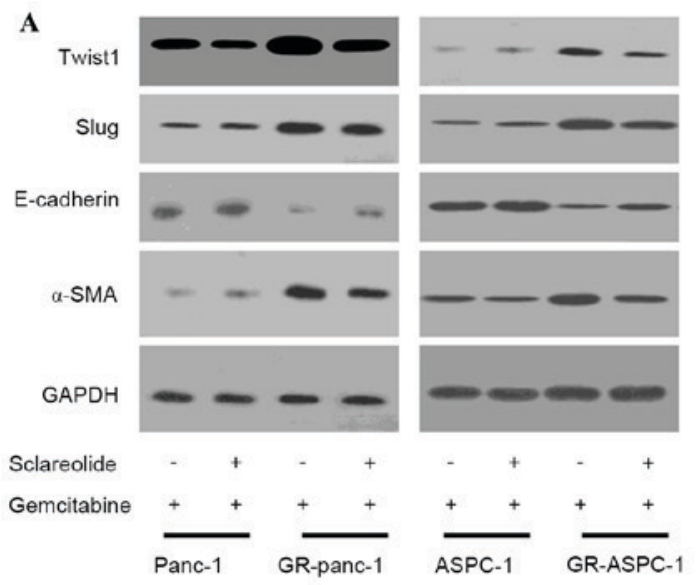

B

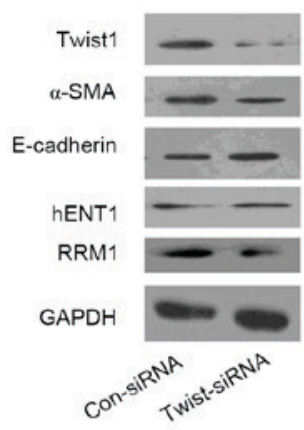

C

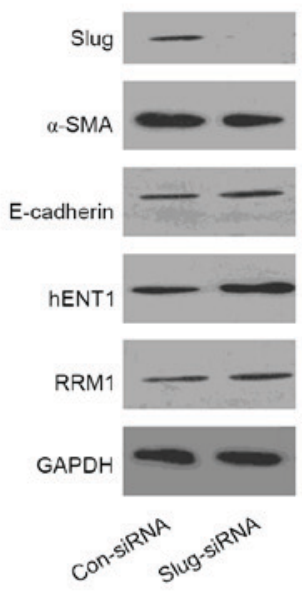

D

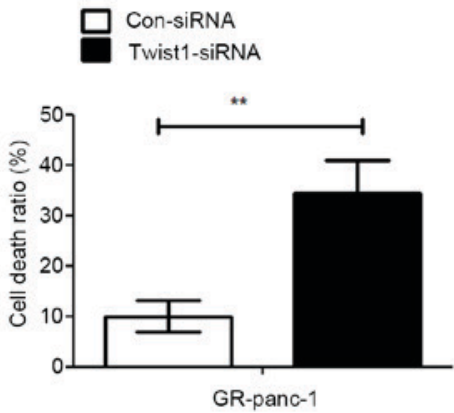

$\mathbf{E}$

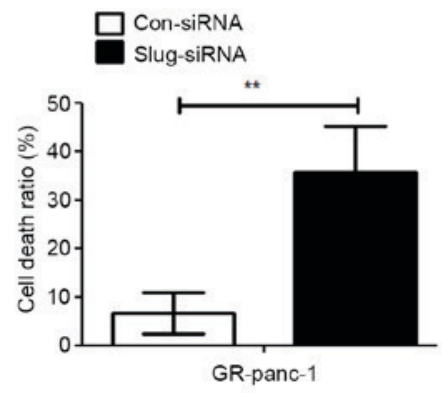

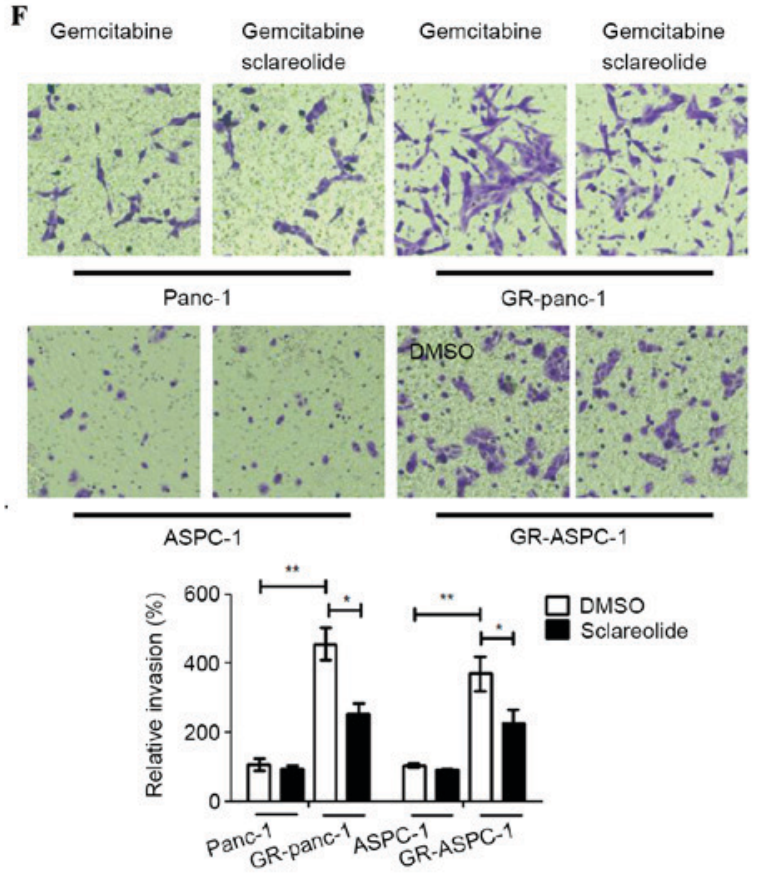

Figure 3. Sclareolide suppresses the EMT phenotype of GR-HPCC through TWIST1 and Slug signals, and recovers the activation of TWIST1 and Slug in GR-HPCCs. HPCCs and GR-HPCCs were treated with $1 \mu \mathrm{m}$ gemcitabine alone or with $10 \mu \mathrm{m}$ sclareolide ( $2 \mathrm{~h}$ pretreatment) and $1 \mu \mathrm{m}$ gemcitabine for $24 \mathrm{~h}$. (A) Sclareolide recovered the activation of TWIST1 and Slug in GR-HPCCs. GR-Panc-1 cells were transfected with control siRNA, (B) TWIST1-siRNA or (C) Slug-siRNA, and expression levels of hENT, RRM1, $\alpha$-SMA and E-cadherin were analyzed. Cell death ratios were analyzed in the (D) TWIST1-siRNA and (E) Slug-siRNA cells using Trypan blue. (F) Sclareolide suppressed the invasive ability of GR-HPCCs, HPCCs and GR-HPCCs treated with $1 \mu \mathrm{m}$ gemcitabine alone or with $10 \mu \mathrm{m}$ sclareolide ( $2 \mathrm{~h}$ pretreatment) for $24 \mathrm{~h}$. Magnification, $\mathrm{x} 400$. ${ }^{*} \mathrm{P}<0.05$ and ${ }^{* * *} \mathrm{P}<0.01$. GR-HPCCs, gemcitabine-resistant human pancreatic cancer cells; hENT1, human equilibrative nucleoside transporter 1; RRM1, ribonucleoside diphosphate reductase 1; $\alpha$-SMA, $\alpha$-smooth muscle actin; siRNA, small interfering RNA.

with gemcitabine alone or combined with sclareolide. The results showed that the expression levels of NICD and Gli1 in the GR-HPCCs were higher, compared with those in the HPCCs, and sclareolide inhibited the expression of NICD and Gli1 (Fig. 4A). In the GR-Panc-1 cells, the expression levels of TWIST1, Slug and RRM1 were inhibited, and the expression of hENT1 was enhanced. Treatment with gemcitabine combined with sclareolide induced an increase in the GR-HPCC death ratio when NICD and Glil were knocked down by siRNA (Fig. 4B-E). These results suggested that sclareolide resensitized the GR-HPCCs to gemcitabine through the NICD/Gli1 pathway.
Sclareolide suppresses gemcitabine-resistant pancreatic tumor growth through apoptosis. In order to clarify the mechanism of sclareolide-stimulated gemcitabine-induced cell death, the apoptosis of GR-HPCCs treated with gemcitabine alone or with sclareolide was detected using Annexin V-FITC and PI. Additionally, the markers of apoptosis, poly (ADP-ribose) polymerase (PARP) and Capase-3 were detected. When the GR-HPCCs were treated with gemcitabine and sclareolide, the apoptotic ratio was higher, and the expression levels of PARP and Capase-3 were higher, compared with the GR-HPCCs treated with gemcitabine alone (Fig. 5A and B). These results showed that the 
A

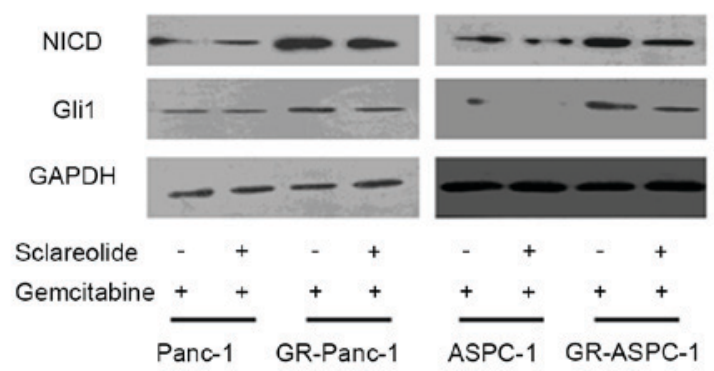

B

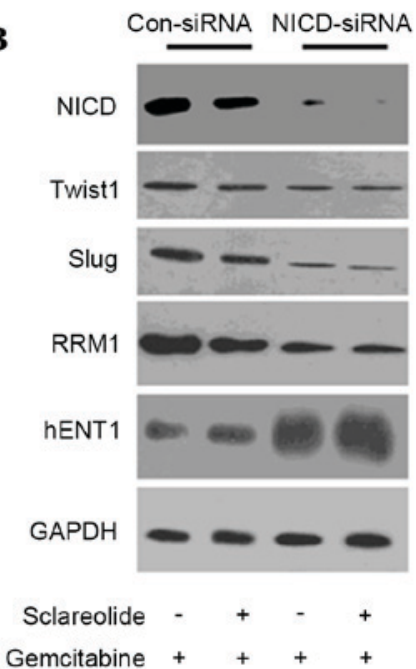

C

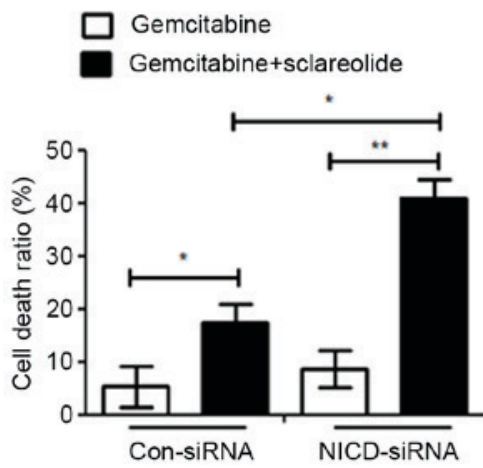

D

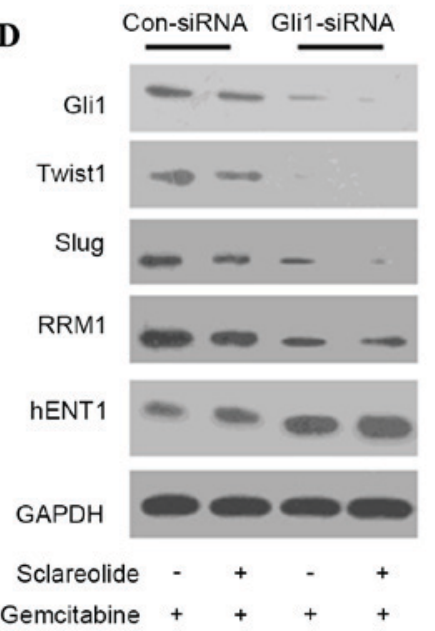

$\mathbf{E}$
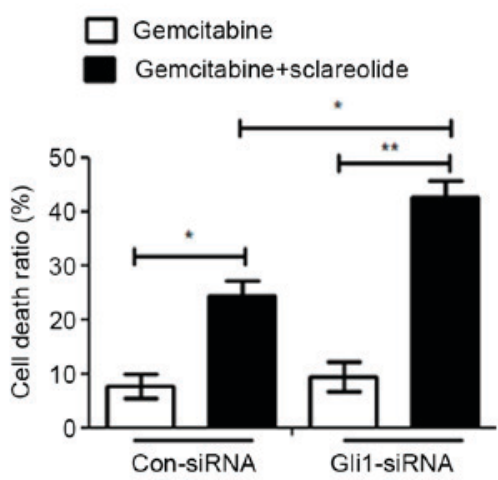

Figure 4. Sclareolide resensitizes GR-HPCCs to gemcitabine through inhibiting NICD/Gli1 signals. HPCCs and GR-HPCCs were treated with $1 \mu \mathrm{m}$ gemcitabine alone or with $10 \mu \mathrm{m}$ sclareolide ( $2 \mathrm{~h}$ pretreatment) and $1 \mu \mathrm{m}$ gemcitabine for $24 \mathrm{~h}$. (A) Expression of NICD/Gli1 was analyzed. (B) GR-Panc-1 cells were transfected with control siRNA or NICD-siRNA, and treated with $1 \mu \mathrm{m}$ gemcitabine alone or with $10 \mu \mathrm{m}$ sclareolide $(2 \mathrm{~h}$ pretreatment) and $1 \mu \mathrm{m}$ gemcitabine for $24 \mathrm{~h}$. (C) Cell death ratios were analyzed using Trypan blue. (D) GR-Panc-1 cells were transfected with control siRNA or Gli1-siRNA, and treated with $1 \mu \mathrm{m}$ gemcitabine alone or with $10 \mu \mathrm{m}$ sclareolide ( $2 \mathrm{~h}$ pretreatment) and $1 \mu \mathrm{m}$ gemcitabine for $24 \mathrm{~h}$. (E) Cell death ratios were analyzed using Trypan blue. ${ }^{*} \mathrm{P}<0.05$ and ${ }^{* *} \mathrm{P}<0.01$. GR-HPCCs, gemcitabine-resistant human pancreatic cancer cells; NICDl, NOTCH 1 intracellular cytoplasmic domain; Gli1, glioma-associated oncogene 1; siRNA, small interfering RNA.

mechanism of sclareolide-stimulated gemcitabine-induced cell death involved stimulating apoptosis. In order to confirm the effect in vivo, nude mice were used to establish a pancreatic tumor xenograft model with Panc-1 or GR-Panc-1 cells to examine the effect of co-treatment with gemcitabine and sclareolide. Through intraperitoneal injection, gemcitabine and sclareolide were administered three times each day, with the sclareolide administered $2 \mathrm{~h}$ prior to gemcitabine administration. As expected, following administration with gemcitabine, the volume of tumors was lower in the nude mice xenografted with Panc-1 cells, compared with the nude mice xenografted with GR-Panc-1 cells. In the nude mice xenografted with GR-Panc-1 cells, the volume of tumors was lower following the co-administration of gemcitabine and sclareolide, compared with that following administration of gemcitabine alone (Fig. 5C). The results of the TUNEL assay showed that co-administrating gemcitabine and sclareolide induced apoptosis and inhibited tumor growth in the xenografted GR-Panc-1 model (Fig. 5D).

\section{Discussion}

In the present study, whether sclareolide promotes gemcitabine-induced pancreatic cancer cell death was investigated in GR-HPCCs and GR-HPCCs with an EMT phenotype. The expression levels of hENT1 were lower, and those of RRM1 were higher in the GR-HPCCs, compared with the HPCCs. Following treatment of the GR-HPCCs with sclareolide and gemcitabine, the altered expression levels of hENT1 and RRM1 were altered, altering the HPCC state via TWIST1/Slug signaling, mediated by the NICD/Gli1 pathway (Fig. 6). It was also found that sclareolide enhanced gemcitabine-induced pancreatic cancer cell death through stimulating apoptosis. In xenografted pancreatic tumors using GR-Panc-1 cells, the co-administration of sclareolide and gemcitabine significantly suppressed tumor growth, compared with gemcitabine alone.

It has been previously reported that hENT1 is a transporter of gemcitabine into and out of the cell, and patients with a 


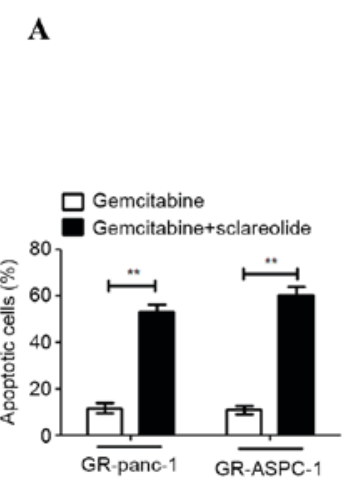

C

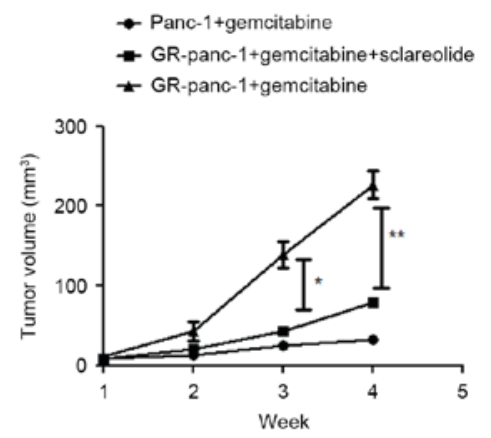

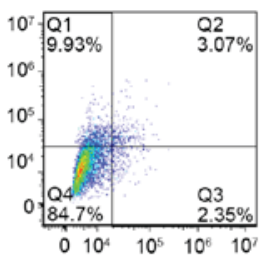

Gemcitabine

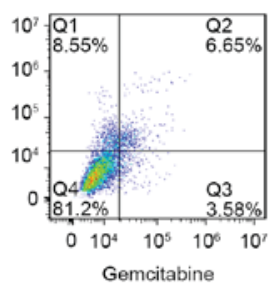

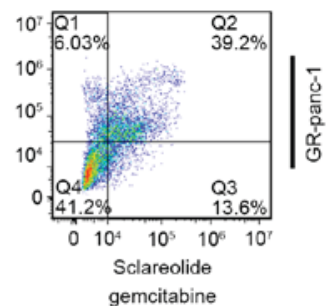

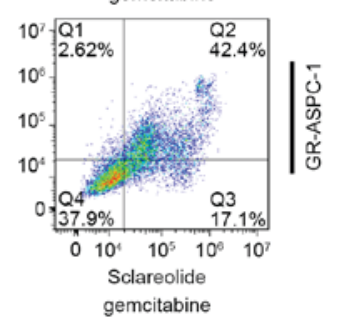

D

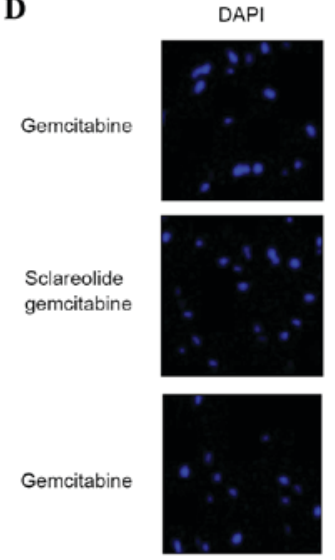

B
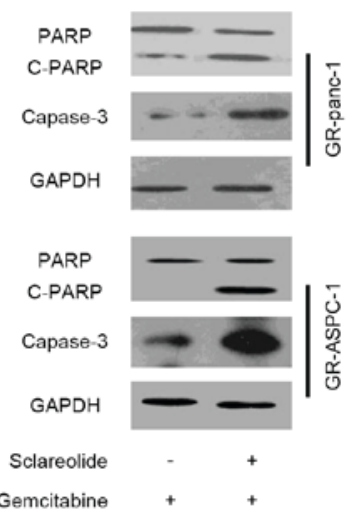

Tunel
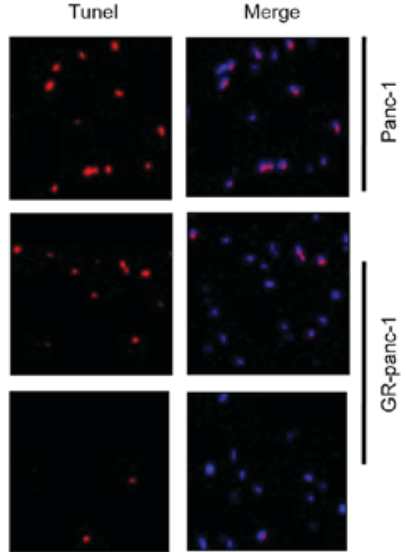

Figure 5. Sclareolide suppresses gemcitabine-resistant pancreatic tumor growth through apoptosis. GR-HPCCs were treated with $1 \mu \mathrm{m}$ gemcitabine alone or with $10 \mu \mathrm{m}$ sclareolide ( $2 \mathrm{~h}$ pretreatment) and $1 \mu \mathrm{m}$ gemcitabine for $24 \mathrm{~h}$. (A) apoptosis was measured using a FACScan flow cytometer. (B) PARP and Capase-3 were measured using immunoblotting. (C) Panc-1 cells and GR-Panc-1 cells were used to establish xenograft transplantation models and, 2 days following inoculation, mice were administered with $10 \mathrm{mg} / \mathrm{kg}$ gemcitabine or were co-administrated with $100 \mathrm{mg} / \mathrm{kg}$ sclareolide ( $2 \mathrm{~h}$ pretreatment) and $10 \mathrm{mg} / \mathrm{kg}$ gemcitabine three times each day via intraperitoneal injection. Tumor volumes were measured every week. (D) An in situ cell death detection kit was used to detect apoptosis. Magnification, $\mathrm{x} 400$. $^{*} \mathrm{P}<0.05$ and ${ }^{* *} \mathrm{P}<0.01$. GR-HPCCs, gemcitabine-resistant human pancreatic cancer cells; PARP, poly (ADP-ribose) polymerase; C-PARP, cleaved PARP.

higher expression of hENT1 have increased survival rates, compared with those with a lower expression of hENT1, particularly in patients with gemcitabine-resistant pancreatic cancer $(21,22)$. RRM1, as a target of gemcitabine is expressed at a high level in patients with gemcitabine-resistant pancreatic cancer, and lower expression levels of RRM1 lead to increased survival rates in patients with gemcitabine-resistant pancreatic cancer $(23,24)$. It has been reported that EMT is in the active state in gemcitabine-resistant pancreatic cancer, and inhibiting EMT can suppress the growth of pancreatic cancer $(10,12)$. Although hENT1 and RRM1 have been found to be associated with gemcitabine-resistant pancreatic cancer, the molecular mechanism remains to be elucidated. Previous reports have stated that Notch is involved in mediating hENT1 and RRM1, with PPAR $\alpha$ and PPAR $\gamma$ mediating hENT1, AKT, phosphoinositide 3-kinase, RAS/ERT and mitogen-activated protein kinase kinase 1/2 mediating RRM1 (25-29). The present study investigated whether the EMT transcriptional factors, TWIST1 and Slug, can suppress the expression of hENT1 and enhance the expression of RRM1 in GR-HPCCs. Sclareolide reversed the mediating effects of TWIST1

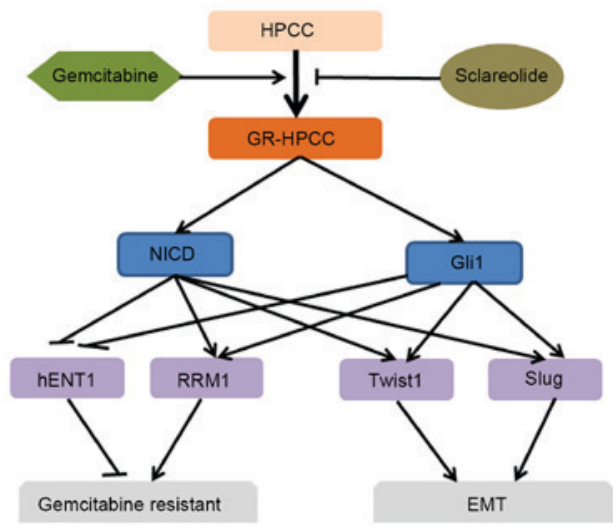

Figure 6. Sclareolide pathway enhances gemcitabine-induced gemcitabine-resistant human pancreatic cancer cell death. HPCCs became GR-HPCCs due to the activation of NICD and Glil. Inhibition of hENT1 and activation of RRM1 contributed to gemcitabine resistance. NICD and Gli1 can activated TWIST1 and Slug, which contributed to EMT. Sclareolide inhibited these alterations. GR-HPCCs, gemcitabine-resistant human pancreatic cancer cells; NICD1, NOTCH1 intracellular cytoplasmic domain; Gli1, glioma-associated oncogene 1; hENT1, human equilibrative nucleoside transporter 1; RRM1, ribonucleoside diphosphate reductase 1; EMT, epithelial to mesenchymal transition. 
and Slug on hENT1 and RRM1 through the inhibition of TWIST1 and Slug. In addition, sclareolide inhibited the EMT phenotype in GR-HPCCs treated with gemcitabine. The activation of the Notch signaling pathway involves three steps, involving the S1, S2 and S3 proteolytic cleavage sites. Following $\gamma$-secretase cleavage at the $\mathrm{S} 3$ site, releasing the soluble NICD, NICD transfers to the nucleus and interacts with the DNA binding protein CBF1/suppressor of Hairless/Lag1, recruits mastermind-like and histone acetyltransferase P300/cAMP response sequence binding protein (CREB) binding protein to activate target gene expression (30-35). The Hh pathway is one of the developmental pathways, involving canonical and non-canonical signaling, and several studies have focused on the potential of targeting Hh signaling as an anticancer strategy, in which targeting Hh signaling downstream of Smoothened (SMO) is important. Activation of GLI transcription factors can promote the transcription of Hh target genes $(36,37)$. GLI1 is one of the members of the GLI transcription factor family, with an exclusively full-length transcriptional activator $(38,39)$. GLI1 is upstream in the signaling pathway, thus targeting GLI1 can be useful in tumors harboring mutations of SMO or mediation downstream of SMO (36). GLI1 is also activated in several important oncogenic pathways, which can inhibit more upstream members of the Hh pathway $(37,39,40)$. In the present study, it was found that NICD and GLI1 were involved in the EMT phenotype of GR-HPCC mediation, and mediated the expression of TWIST1 and Slug, which were mediators of hENT1 and RRM1. hENT1 and RRM1 were important in resensitizing gemcitabine-resistant pancreatic cancer to gemcitabine. Although NICD and GLI1 led to significant alterations in HPCCs and GR-HPCCs, sclareolide reversed the alterations in GR-HPCCs when co-treated with gemcitabine, and contributed to gemcitabine-induced cell death in GR-HPCCs, resensitizing GR-HPCCs to gemcitabine. In order to clarify the mechanism underlying sclareolide-enhanced gemcitabine-induced GR-HPCC death, apoptosis was detected in GR-HPCCs, and the results showed that sclareolide enhanced gemcitabine-induced GR-HPCC death through the activation of apoptosis. Using a tumor xenograft model to evaluate the effect of sclareolide and gemcitabine co-treatment in vivo, the present study demonstrated that single administration of gemcitabine suppressed tumor growth in the gemcitabine-sensitive cell xenograft model, however, it did not suppress tumor growth in the gemcitabine-resistant cell xenografted model. When co-administered with sclareolide and gemcitabine, the tumor growth was significantly inhibited in the gemcitabine-resistant cell xenografted model. The results obtained using the xenograft model supported the in vitro results. Furthermore, in situ apoptosis detection revealed that sclareolide and gemcitabine co-treatment in the gemcitabine-sensitive cell xenografted model led to the suppression of tumor growth through the activation of apoptosis.

In conclusion, the present study demonstrated that NICD/GLI1-TWIST1/Slug mediated the EMT phenotype of GR-HPCCs, and they are a novel mechanism of gemcitabine-resistance in pancreatic cancer. In addition, the present study indicated that sclareolide resensitized GR-HPCCs to gemcitabine through the NICD and GLI1 pathway, targeting hENT1 and RRM1 signals, inhibiting the gemcitabine-induced EMT phenotype and enhancing gemcitabine-induced GR-HPCC death through the activation of apoptosis. Gemcitabine combined with sclareolide may be a novel and efficient therapeutic strategy for patients with gemcitabine-resistant pancreatic cancer.

\section{Acknowledgements}

The present study was supported by the National Science Foundation of China (grant no. 81472753).

\section{References}

1. Siegel R, Naishadham D and Jemal A: Cancer statistics, 2013. CA Cancer J Clin 63: 11-30, 2013.

2. Seicean A, Petrusel L and Seicean R: New targeted therapies in pancreatic cancer. World J Gastroenterol 21: 6127-6145, 2015

3. Massari F, Santoni M, Ciccarese C, Brunelli M, Conti A, Santini D, Montironi R, Cascinu S and Tortora G: Emerging concepts on drug resistance in bladder cancer: Implications for future strategies. Crit Rev Oncol Hematol 96: 81-90, 2015.

4. de Sousa Cavalcante L and Monteiro G: Gemcitabine: Metabolism and molecular mechanisms of action, sensitivity and chemoresistance in pancreatic cancer. Eur J Pharmacol 741: 8-16, 2014.

5. Nordh S, Ansari D and Andersson R: hENT1 expression is predictive of gemcitabine outcome in pancreatic cancer: A systematic review. World J Gastroenterol 20: 8482-8490, 2014.

6. Santini D, Schiavon G, Vincenzi B, Cass CE, Vasile E, Manazza AD, Catalano V, Baldi GG, Lai R, Rizzo S, et al: Human equilibrative nucleoside transporter 1 (hENT1) levels predict response to gemcitabine in patients with biliary tract cancer (BTC). Curr Cancer Drug Targets 11: 123-129, 2011.

7. Lamba JK: Genetic factors influencing cytarabine therapy. Pharmacogenomics 10: 1657-1674, 2009.

8. Jordheim LP and Dumontet C: Do hENT1 and RRM1 predict the clinical benefit of gemcitabine in pancreatic cancer? Biomark Med 7: 663-671, 2013.

9. Jordheim LP, Sève P, Trédan $O$ and Dumontet $C$ : The ribonucleotide reductase large subunit (RRM1) as a predictive factor in patients with cancer. Lancet Oncol 12: 693-702, 2011.

10. Shah AN, Summy JM, Zhang J, Park SI, Parikh NU and Gallick GE: Development and characterization of gemcitabine-resistant pancreatic tumor cells. Ann Surg Oncol 14: 3629-3637, 2007.

11. Arumugam $\mathrm{T}$, Ramachandran $\mathrm{V}$, Fournier KF, Wang $\mathrm{H}$, Marquis L, Abbruzzese JL, Gallick GE, Logsdon CD, McConkey DJ and Choi W: Epithelial to mesenchymal transition contributes to drug resistance in pancreatic cancer. Cancer Res 69: 5820-5828, 2009.

12. Schaeffer DF, Assi K, Chan K, Buczkowski AK, Chung SW, Scudamore CH, Weiss A, Salh B and Owen DA: Tumor expression of integrin-linked kinase (ILK) correlates with the expression of the E-cadherin repressor snail: An immunohistochemical study in ductal pancreatic adenocarcinoma. Virchows Arch 456: 261-268, 2010.

13. Atta-ur-Rahman, Farooq A and Choudhary MI: Microbial transformation of sclareolide. J Nat Prod 60: 1038-1040, 1997.

14. González MA, Mancebo-Aracil J, Tangarife-Castaño V, Agudelo-Goméz L, Zapata B, Mesa-Arango A and Betancur-Galvis L: Synthesis and biological evaluation of (+)-labdadienedial, derivatives and precursors from (+)-sclareolide. Eur J Med Chem 45: 4403-4408, 2010.

15. Livak KJ and Schmittgen TD: Analysis of relative gene expression data using real-time quantitative PCR and the 2(-Delta Delta C(T)) method. Methods 25: 402-408, 2001.

16. Jung HY and Yang J: Unraveling the TWIST between EMT and cancer stemness. Cell Stem Cell 16: 1-2, 2015.

17. Shih JY and Yang PC: The EMT regulator slug and lung carcinogenesis. Carcinogenesis 32: 1299-1304, 2011.

18. Tian Y, Xu Y, Fu Q, Chang M, Wang Y, Shang X, Wan C, Marymont JV and Dong Y: Notch inhibits chondrogenic differentiation of mesenchymal progenitor cells by targeting Twist1. Mol Cell Endocrinol 403: 30-38, 2015. 
19. Joost S, Almada LL, Rohnalter V, Holz PS, Vrabel AM, Fernandez-Barrena MG, McWilliams RR, Krause M, Fernandez-Zapico ME and Lauth M: GLI1 inhibition promotes epithelial-to-mesenchymal transition in pancreatic cancer cells. Cancer Res 72: 88-99, 2012.

20. Gopalakrishnan N, Sivasithamparam ND and Devaraj H: Synergistic association of Notch and NFKB signaling and role of Notch signaling in modulating epithelial to mesenchymal transition in colorectal adenocarcinoma. Biochimie 107: 310-318, 2014.

21. Strimpakos AS, Syrigos KN and Saif MW: Pharmacogenomics in pancreatic adenocarcinoma: New data and their clinical implications. JOP 14: 359-362, 2013.

22. Damaraju VL, Scriver T, Mowles D, Kuzma M, Ryan AJ, Cass CE and Sawyer MB: Erlotinib, gefitinib, and vandetanib inhibit human nucleoside transporters and protect cancer cells from gemcitabine cytotoxicity. Clin Cancer Res 20: 176-186, 2014.

23. Minami K, Shinsato Y, Yamamoto M, Takahashi H, Zhang S, Nishizawa Y, Tabata S, Ikeda R, Kawahara K, Tsujikawa K, et al: Ribonucleotide reductase is an effective target to overcome gemcitabine resistance in gemcitabine-resistant pancreatic cancer cells with dual resistant factors. J Pharmacol Sci 127: $319-325,2015$

24. Xie H, Jiang W, Jiang J, Wang Y, Kim R, Liu X and Liu X: Predictive and prognostic roles of ribonucleotide reductase M1 in resectable pancreaticadenocarcinoma. Cancer 119: 173-181, 2013.

25. Montero TD, Racordon D, Bravo L, Owen GI, Bronfman ML and Leisewitz AV: PPAR $\alpha$ and PPAR $\gamma$ regulate the nucleoside transporter hENT1. Biochem Biophys Res Commun 419: 405-411, 2012.

26. Koo JS and Kim H: Hypoxia-related protein expression and its clinicopathologic implication in carcinoma of unknown primary. Tumour Biol 32: 893-904, 2011.

27. Tassone P, Di Martino MT, Ventura M, Pietragalla A, Cucinotto I, Calimeri T, Bulotta A, Neri P, Caraglia M and Tagliaferri P: Loss of BRCA1 function increases the antitumor activity of cisplatin against human breast cancer xenografts in vivo. Cancer Biol Ther 8: 648-653, 2009.

28. El-Khoueiry AB, Ramanathan RK, Yang DY, Zhang W, Shibata S, Wright JJ, Gandara D and Lenz HJ: A randomized phase II of gemcitabine and sorafenib versus sorafenib alone in patients with metastatic pancreatic cancer. Invest New Drugs 30: $1175-1183,2012$
29. Vena F, Causi EL, Rodriguez-Justo M, Goodstal S, Hagemann T, Hartley JA and Hochhauser D: The MEK1/2 inhibitor Pimasertib enhances gemcitabine efficacy in pancreatic cancer models by altering protein levels of ribonucleotide reductase subunit-1 (RRM1). Clin Cancer Res 21: 5563-5577, 2015.

30. Grishina IB: Mini-review: Does notch promote or suppress cancer? New findings and old controversies. Am J Clin Exp Urol 3: 24-27, 2015.

31. Uzdensky AB, Demyanenko SV and Bibov MY: Signal transduction in human cutaneous melanoma and target drugs. Curr Cancer Drug Targets 13: 843-866, 2013.

32. Tang SC and Chen YC: Novel therapeutic targets for pancreatic cancer. World J Gastroenterol 20: 10825-10844, 2014.

33. Li L and Leung PS: Use of herbal medicines and natural products: An alternative approach to overcoming the apoptotic resistance of pancreatic cancer. Int J Biochem Cell Biol 53: 224-236, 2014.

34. Schwanbeck R: The role of epigenetic mechanisms in Notch signaling during development. J Cell Physiol 230: 969-981, 2015.

35. Takebe N, Nguyen D and Yang SX: Targeting notch signaling pathway in cancer: Clinical development advances and challenges. Pharmacol Ther 141: 140-149, 2014.

36. Gonnissen A, Isebaert S and Haustermans K: Targeting the Hedgehog signaling pathway in cancer: Beyond Smoothened. Oncotarget 6: 13899-13913, 2015.

37. Aberger F, Ruiz I and Altaba A: Context-dependent signal integration by the GLI code: The oncogenic load, pathways, modifiers and implications for cancer therapy. Semin Cell Dev Biol 33: 93-104, 2014

38. Merchant JL and Saqui-Salces M: Inhibition of Hedgehog signaling in the gastrointestinal tract: Targeting the cancer microenvironment. Cancer Treat Rev 40: 12-21, 2014.

39. Drenkhahn SK, Jackson GA, Slusarz A, Slusarz A, Starkey NJ and Lubahn DB: Inhibition of hedgehog/Gli signaling by botanicals: A review of compounds with potential hedgehog pathway inhibitory activities. Curr Cancer Drug Targets 13: 580-595, 2013.

40. Perrot CY, Javelaud D and Mauviel A: Overlapping activities of TGF- $\beta$ and Hedgehog signaling in cancer: Therapeutic targets for cancer treatment. Pharmacol Ther 137: 183-199, 2013. 